\title{
A Novel Concept of Ribless Synchronous Reluctance Motor for Enhanced Torque Capability
}

\author{
Yuli Bao, Michele Degano, Senior Member, IEEE, Shuo Wang, Member, IEEE, Liu Chuan, Zhuang Xu, \\ Senior Member, IEEE, He Zhang Senior Member, IEEE, and Chris Gerada Senior Member, IEEE
}

\begin{abstract}
The rotor structure of synchronous reluctance machines (SynRel) is conventionally retained mechanically by iron ribs. In this paper a novel structure for high speed synchronous reluctance rotor is presented. The novelty of this work is the proof of a concept of SynRel machine without iron ribs. Structurally, the rotor iron lamination segments are embedded in an adhesive resin material with high temperature resistance and mechanical strength. Three four-pole SynRel machines have been designed with the target of improving motor torque, and compared for different ribs configuration. It has been shown that the proposed motor performs enhanced torque, power factor and efficiency with respect to conventional SynRel with iron ribs. An extensive sensitivity analysis of the ribless rotor geometry is carried out, followed by both mechanical analysis and experimental over speed test to guarantee its robustness above the operating speed range. The manufacturing procedure of this novel rotor is introduced. Finally, the experimental results on both SynRel prototypes are presented, showing the increase in torque, power factor and efficiency of the proposed solution. This work is a first step towards the definition of a viable and novel solution of SynRel machines with improved performance.
\end{abstract}

Index Terms-Torque enhancement, sensitivity analysis, ribless rotor design, synchronous reluctance machines (SynRel)

\section{INTRODUCTION}

$\mathbf{S}$ YNCHRONOUS Reluctance (SynRel) machines have gained increasing interests in several applications thanks to their advantages with respect to induction machines [1]-[4]. It has been shown that they exhibit good torque capability,

Manuscript received December, 12, 2018; revised February, 8, 2019; accepted April, 12, 2019. This work was supported by the China NSFC under Grant 51607099 and Ningbo Science\&Technology Bureau 2018B10002 and 2017D10029.

Yuli Bao, Michele Degano, Shuo Wang, Chuan Liu, Zhuang Xu, He Zhang and Chris Gerada are with Power Electronics, Machines and Control group and Key Laboratory of More Electric Aircraft Technology of Zhejiang Province, University of Nottingham Ningbo China, Ningbo 315100, China (email: Yuli.Bao@nottingham.edu.cn michele.degano@nottingham.edu.cn; zassshwn@nottingham.edu.cn; Chuan.Liu@nottingham.edu.cn; John.xu@nottingham.edu.cn; He.Zhang@nottingham.edu.cn; Chris Gerada@nottingham.edu.cn).

Michele Degano, He Zhang and Chirs Gerada are with University of Nottingham, NG7 2RD, U.K. (email: michele.degano@nottingham.ac.uk; He.Zhang@nottingham.ac.uk; Chirs Gerada@nottingham.ac.uk). wide operating speed range and high efficiency because of the rotor anisotropy [5]. Their use is especially beneficial when a low-cost machine is required and if the use of permanent magnets (PMs) is not desired. Due to the absence of PMs, their application field is limited to low power density range, as they cannot compete with Permanent Magnet Synchronous Machines (PMSM) [6]. A number of research activities have demonstrated that with an optimal rotor design or skewing techniques, the torque ripple can be significantly reduced [7][10]. Another aspect that can be considered a downside of SynRel motors is the relatively poor power factor [11]. The low power factor is depending on two main factors: the absence of any excitation in the rotor structure and the presence of the iron ribs, which are normally necessary to guarantee mechanical robustness of the rotor against centrifugal forces [12]. In the past other types of rotors like axially laminated anisotropy (ALA) rotors have been prototyped and tested. However, due to their manufacturing complexity and high rotor iron loss they have hardly found any further development [13]. In order to exhibit a good torque, the conventional SynRel is characterized by a small airgap and a high anisotropic rotor as shown in Fig. 1. Several rotor flux barriers force the flux to flow through given iron paths.

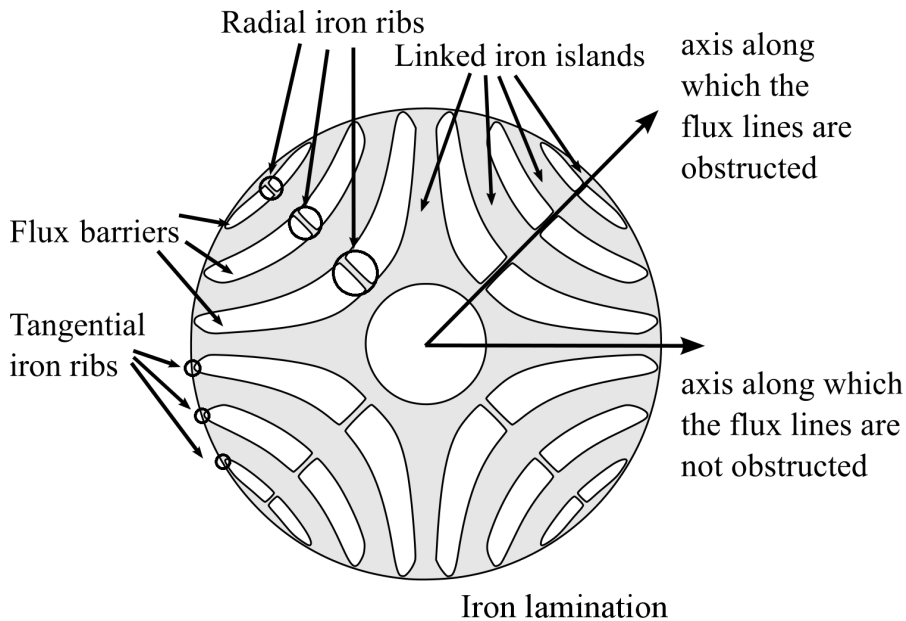

Fig. 1. Rotor sketch: four-pole synchronous reluctance rotor with three flux barriers per pole. Benchmark prototype (M1). 
The function of iron ribs is purely structural. However, as part of the rotor magnetic circuit, they affect the electromagnetic performance of the machine because they act as a short circuit for the flux between the iron islands. In order to saturate those iron ribs, a "magnetizing" current from the stator winding is required. As a consequence, this current is not contributing to the torque production and it results in a generation of flux leakage that is closing through the rotor iron ribs [14]. One of the alternative options is including PMs inset within the flux barriers for the same purpose of saturating the iron ribs [15], [16].

For those applications where the PMs are not allowed, the only option to enhance torque production is to optimise the rotor geometry for the highest saliency ratio and with the minimum iron ribs thickness [17]. The latter is defined by the size of the rotor, mass and rotational speed to guarantee a safety margin for mechanical robustness. In most of the designs, the minimum thickness of the ribs is limited not only by mechanical reasons but by the minimum manufacturing tolerances [18]. Normally, ribs thickness below $0.5 \mathrm{~mm}$ are not recommended no matter whether the laminations are manufactured by punching, laser or electro erosion cutting methods [6].

In this work, a novel concept of ribless machine is proposed aiming to demonstrate that an ideal SynRel machine designed without iron ribs could lead to an improved torque, power factor and efficiency with respect to conventional SynRel motors. The goal has been achieved through the design and manufacturing of a novel rotor structure filled with an epoxy resin.

This paper is organised in four main parts. In section II, the geometry of three different rotors is introduced. Each machine is analysed via Finite Element (FE) demonstrating the advantages of the novel concept. Section III presents a detailed torque sensitivity analysis of the novel rotor considering different parameters. In section IV, a structural analysis is carried out to understand the stresses on the rotor structure. These are supported by over speed tests. Finally, the experimental results are shown in section $\mathrm{V}$ to prove the feasibility and potential of the proposed concept.

\section{SynREL DESIGNS AND ANALYSIS}

\section{A. Reference stator}

In order to guarantee the highest saliency ratio an Integral Slot Distributed Winding (ISDW) has been chosen. Since SynRel machines present a high rotor anisotropy, it has been demonstrated that this winding arrangement is the most effective solution compared to Fractional Slot Concentrated winding (FSCW) [19], [20]. The stator and winding configurations of the three machines refer to the benchmark SynRel in [6]. They share the same stator with ISDW as well as the same air-gap length $0.35 \mathrm{~mm}$. A portion of the stator geometry is shown in Fig. 2. The parameters shown in Fig. 2 are identified in Table I along with winding configurations.

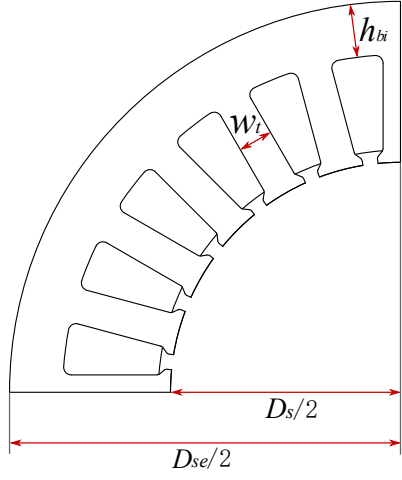

(a)

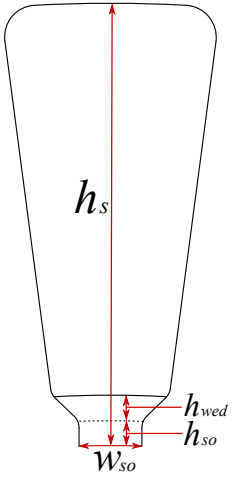

(b)
Fig. 2. Stator sketch (a) and slot detail (b).

TABLE I

STATOR AND WINDING PARAMETERS

\begin{tabular}{cccc}
\hline \hline Stator geometry & Label & Value & unit \\
\hline Stator outer diameter & $D_{s e}$ & 102 & $\mathrm{~mm}$ \\
Stator inner diameter & $D_{s}$ & 60.1 & $\mathrm{~mm}$ \\
Number of slots & $Q_{s}$ & 24 & - \\
Slot height & $h_{s}$ & 14 & $\mathrm{~mm}$ \\
Back iron height & $h_{b i}$ & 6.95 & $\mathrm{~mm}$ \\
Tooth width & $W_{t}$ & 4.54 & $\mathrm{~mm}$ \\
Slot opening width & $W_{s o}$ & 2 & $\mathrm{~mm}$ \\
Slot opening height & $h_{s o}$ & 0.8 & $\mathrm{~mm}$ \\
Wedge height & $h_{\text {wed }}$ & 0.8 & $\mathrm{~mm}$ \\
Stack length & $L_{s t k}$ & 50 & $\mathrm{~mm}$ \\
\hline Winding configuration & & & $\mathrm{unit}$ \\
\hline Number of turns per slot & $N_{k}$ & 38 & - \\
Slot fill factor & $k_{f i l l}$ & 0.4 & - \\
Phase number & $m$ & 3 & - \\
Number of slots per phase per pole & $q$ & 2 & - \\
\hline \hline
\end{tabular}

\section{B. Reference rotor geometries}

All rotors have four poles and the barrier distribution is symmetrical. Fig. 3 and Fig. 4 are showing the rotors of the three machines considered and compared in this section:

- M1: with both tangential and radial ribs;

- M2: with only tangential ribs;

- M3: novel resin-aided ribless rotor.

Fig. 3 shows one pole of the conventional four-pole SynRel rotors. They are both characterized by three flux barriers per pole where M1 features all the ribs while M2 has only the tangential ones. In Fig. 4 a sketch of the proposed novel resin aided SynRel rotor M3 is presented.

It is characterized by two flux barriers per pole and one cutoff region. All the edges of flux barriers are drawn based on the N. E. Joukowski airfoil potential function [21] according to the 'natural flux lines' method proposed in [5]. Two main differences can be noticed between the conventional rotors (M1 and M2) with respect to the M3. The barriers are filled with resin and the tangential and radial iron ribs are completely removed thanks to the structural support of the introduced material. 


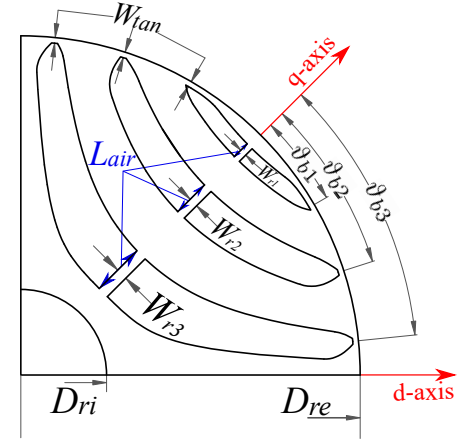

(a)

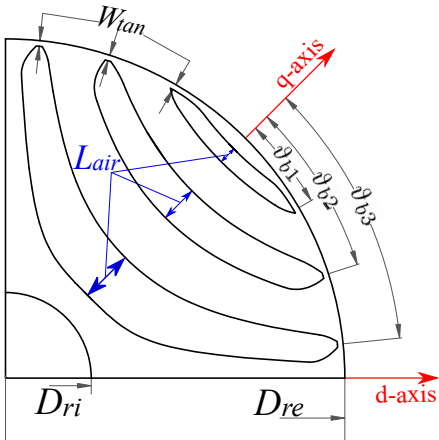

(b)
Fig. 3. Rotor sketches: conventional SynRel rotor pole with all ribs M1 (a) and with tangential ribs only M2 (b).

In addition, the first barrier of M3 has been replaced by a cut-off region, which will also serve as a slot for the resin (see Fig. 4).

The main geometrical parameters considered are summarised below:

- $D_{r e}$ and $D_{r i}$ are the rotor outer and inner Diameters, respectively and $L_{s t k}$ is the lamination stack length;

- $\vartheta_{b 1}, \vartheta_{b 2}$, and $\vartheta_{b 3}$ are flux barrier position angles;

- $W_{r 1}, W_{r 2}$ and $W_{r 3}$ are the radial ribs thickness in M1;

- $W_{t a n}$ is tangential rib thickness in M1 and M2;

- $\Delta b 2$ and $\Delta b 3$ are two barrier end opening angles in M3;

- $C_{c u t}$ is the length from the rotor center to the center of cut-off region on $q$-axis in M3.

In Table II, the dimensions of the three machines are summarised. The optimized parameters of M1, M2 and M3 are obtained through a genetic algorithm (MOGA-II) optimization via modeFrontier [22], which is deeply described in [16] and [23]. The two objectives are to maximize the average torque and to minimize the torque ripple. Among the Pareto front solutions of M3, shown in Fig. 5, the marked one (selected point) is chosen as a reference machine for further analysis.

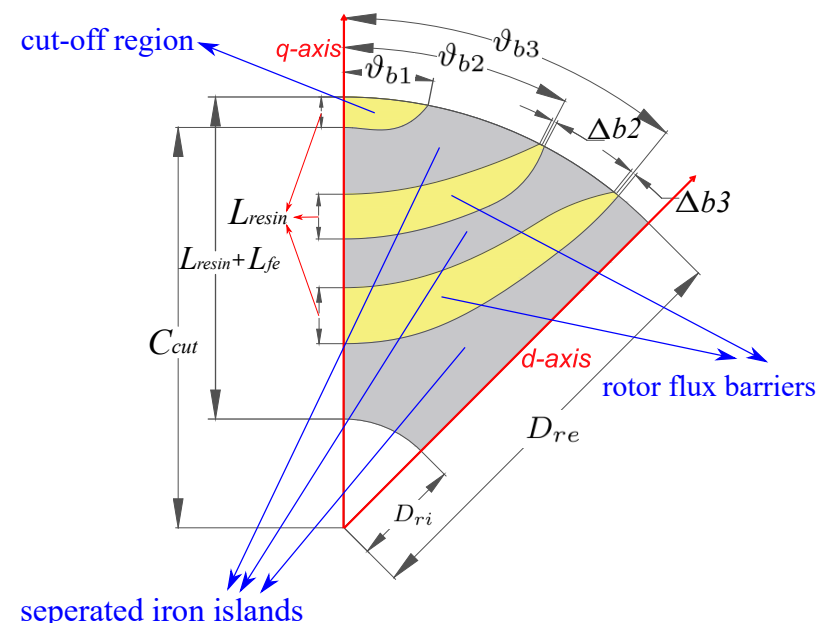

Fig. 4. Rotor sketch: novel resin aided SynRel rotor with two flux barriers per pole and cut off region (M3).
It matches $1.35 \mathrm{Nm}$ torque and a relatively low torque ripple. The geometrical parameters are reported in Table II. In M3,

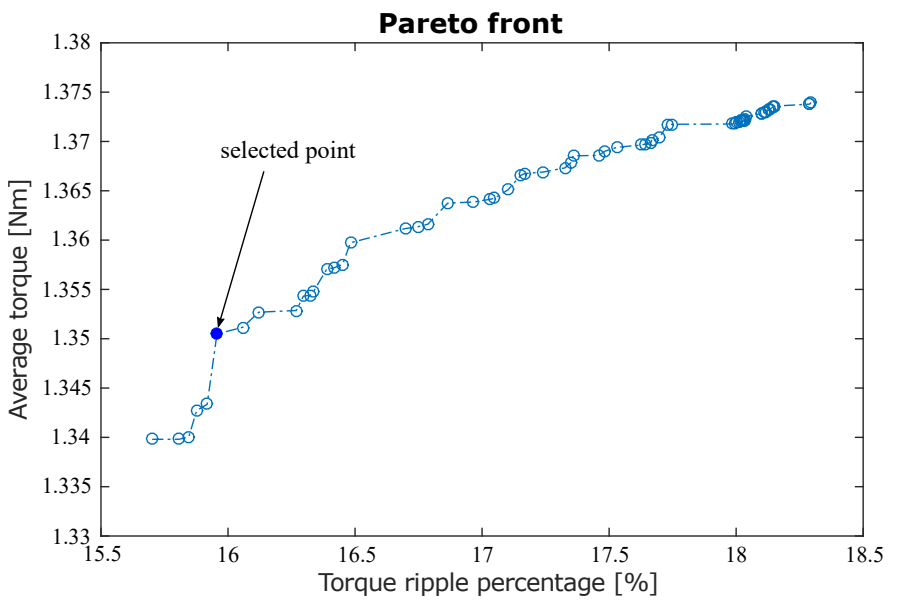

Fig. 5. Pareto front resulting from M3 optimization.

the epoxy resin in both barriers and cut-off regions is holding the iron lamination segments to form a mechanically robust structure. A 3D rotor sketch is shown in Fig. 6 with a clearer view of the two resin end-caps. All the transversally laminated iron islands are held together by the adhesive epoxy resin. Since SynRel machines saturation is strongly dependent by the thickness of the flux barriers, it is common to define an insulation coefficient $k_{\text {air }}$ [24] which is a ratio between $L_{\text {air }}$ (length of air along $q$-axis for conventional M1 and M2, $L_{r e s i n}$ in M3 case) and $D_{r e}-D_{r i}$ (difference between rotor outer and inner diameters). Each flux barrier's thickness and the cut-off region of $\mathrm{M} 3$, which is modified by a cubic function depending on two parameters $\left(\vartheta_{b 1}, C_{c u t}\right)$, have been analysed by means of finite element simulations in order to obtain a desired saturation level in the iron magnetic paths.

TABLE II

Rotor GeOMETRICAL Dimensions

\begin{tabular}{|c|c|c|c|c|}
\hline Motor & M1 & M2 & M3 & unit \\
\hline $\begin{array}{c}\text { iron bridges } \\
\text { designed maximum speed }\end{array}$ & $\begin{array}{c}\tan \text { and radial } \\
16000\end{array}$ & $\begin{array}{l}\text { only } \tan \\
8000\end{array}$ & $\begin{array}{c}\text { no } \\
16000\end{array}$ & $\begin{array}{c}- \\
\text { rpm }\end{array}$ \\
\hline fixed parameters & 7 & 4 & 3 & No. \\
\hline$D_{r e}$ & 59.4 & 59.4 & 59.4 & $\mathrm{~mm}$ \\
\hline$D_{r i}$ & 15 & 15 & 15 & $\mathrm{~mm}$ \\
\hline$L_{s t k}$ & 50 & 50 & 50 & $\mathrm{~mm}$ \\
\hline$W_{\text {tan }}$ & 0.5 & 0.5 & - & $\mathrm{mm}$ \\
\hline$W_{r 1}$ & 0.6 & - & - & $\mathrm{mm}$ \\
\hline$W_{r 2}$ & 0.8 & - & - & $\mathrm{mm}$ \\
\hline$W_{r 3}$ & 1 & - & - & $\mathrm{mm}$ \\
\hline optimized input parameters & 4 & 4 & 7 & No. \\
\hline$\vartheta_{b 1}$ & 14.85 & 14.7 & 11.26 & deg \\
\hline$\vartheta_{b 2}$ & 27.1 & 27.15 & 27.36 & deg \\
\hline$\vartheta_{b 3}$ & 39.2 & 39.2 & 39.18 & deg \\
\hline$\Delta b 2$ & - & - & 0.36 & deg \\
\hline$\Delta b 3$ & - & - & 0.4 & deg \\
\hline$C_{\text {cut }}$ & - & - & 29.6 & $\mathrm{~mm}$ \\
\hline$k_{a i r}$ & 0.43 & 0.39 & 0.32 & - \\
\hline
\end{tabular}




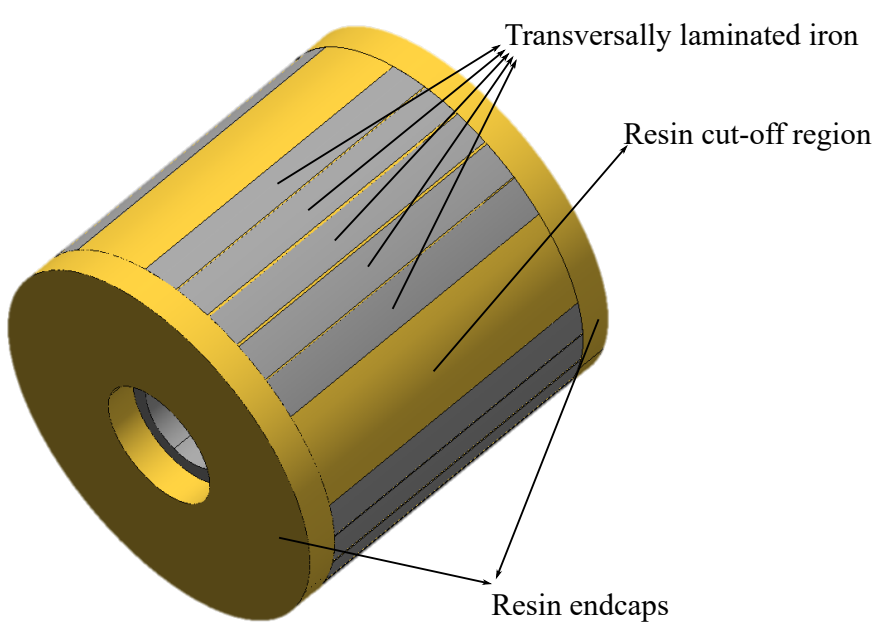

Fig. 6. 3D rotor sketch: the proposed ribless rotor (M3). Resin (yellow) and laminations (grey).

The thickness of the iron bridges of M1 and M2 have been chosen according to the sizing method presented in [25] where a detailed analysis on the SynRel speed capability is given. For example, referring to Fig. 1, both the radial and tangential iron ribs have to guarantee a robust structure and resist to the centrifugal forces insisting on rotor parts. In general, the tangential iron ribs are less mechanically stressed with respect to the radial ones [26]. However, if the central ribs are removed (M2), it will induce a higher stress to the tangential ribs. Consequently, the maximum rotating speed of the machine is decreased (in this case 8000rpm with a safety factor of 1.5 ).

\section{Motor characteristics comparison}

In this section, the three SynRel motors (M1, M2 and M3), presented in section II-B, with optimized rotor geometry for torque production have been selected for comparison.

The static torque as a function of the current angle has been determined by means of FE simulations (with MagNet

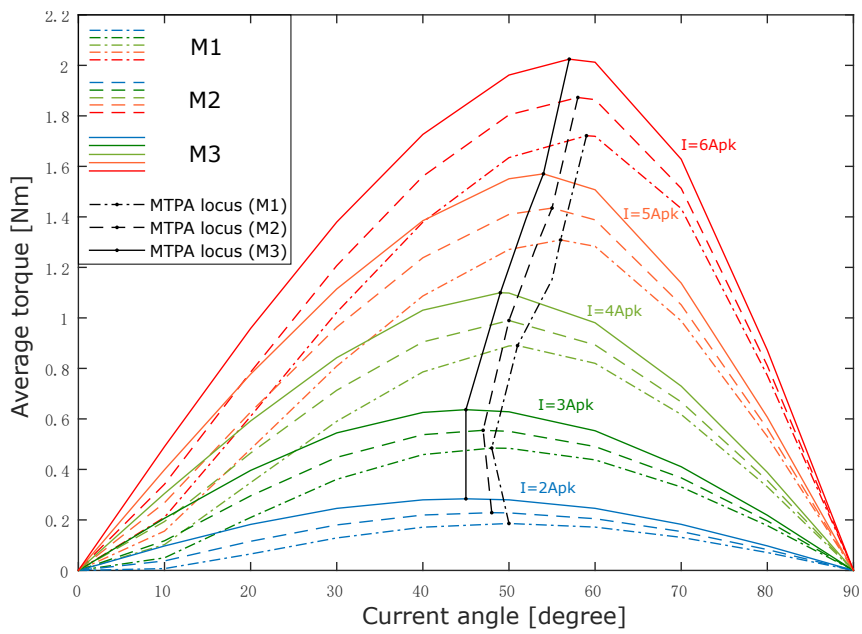

Fig. 7. Static torque comparison of $\mathrm{M} 1, \mathrm{M} 2$ and $\mathrm{M} 3$ under different current loadings.

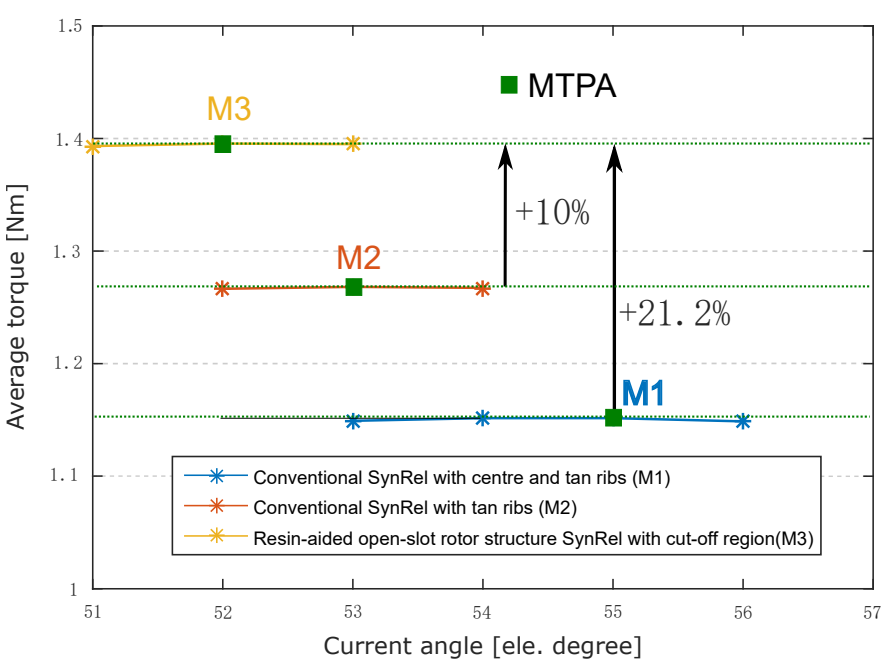

Fig. 8. Average torque comparison at 4.62Apk.

2D software) for all motors. The results are shown in Fig. 7 under different current loadings. It can be noted that for the same current the average torque of M3 is the largest with respect to M1 and M2.

This confirms that the absence of iron ribs can significantly improve the torque performance. Always referring to Fig. 7, for the same current loading the MTPA locus of M3 is given by lower current angles as highlighted with the continuous line. To give a clearer idea of what torque improvement can be ideally achieved by removing the iron ribs, a comparison is given in Fig. 8 for the same phase current of 4.62Apk. It is worth noticing that $\mathrm{M} 3$ with the novel rotor structure proposed can achieve an average torque of $1.395 \mathrm{Nm}$, which is $21.2 \%$ and $10 \%$ higher with respect to M1 and M2 correspondingly.

A summary of the main output characteristics of the three motors, at the rated speed of 6000rpm, is given in Table III. This clearly shows that for the same torque demand, i.e. $1.15 \mathrm{Nm}$, the novel M3 present some benefits:

- the phase peak current is reduced by about $11.1 \%$ compared to the original 4.62Apk in M1;

TABLE III

FEM PERFORMANCE COMPARISON @ 6000 RPM

\begin{tabular}{ccccc}
\hline \hline Motor & M1 & M2 & M3 & unit \\
\hline$T_{\text {avg }}$ & 1.15 & 1.15 & 1.15 & $\mathrm{Nm}$ \\
$P_{\text {out }}$ & 722.6 & 722.6 & 722.6 & $\mathrm{~W}$ \\
\hline$I_{p k}$ & 4.62 & 4.36 & 4.11 & $\mathrm{Apk}$ \\
Reduction & - & -5.6 & -11.1 & $\%$ \\
\hline MTPA $A_{\text {angle }}$ & 55 & 52 & 51 & degree \\
CopperLoss & 38.8 & 34.6 & 30.7 & $\mathrm{~W}$ \\
StatorIronLoss & 14 & 13.1 & 12.7 & $\mathrm{~W}$ \\
RotorIronLoss & 4.9 & 4.5 & 4.2 & $\mathrm{~W}$ \\
\hline PowerFactor & 0.62 & 0.68 & 0.72 & - \\
Improvement & - & 9.7 & 16.1 & $\%$ \\
\hline Efficiency & 92.6 & 93.3 & 93.8 & $\%$ \\
Improvement & - & 0.7 & 1.2 & $\%$ \\
\hline \hline
\end{tabular}




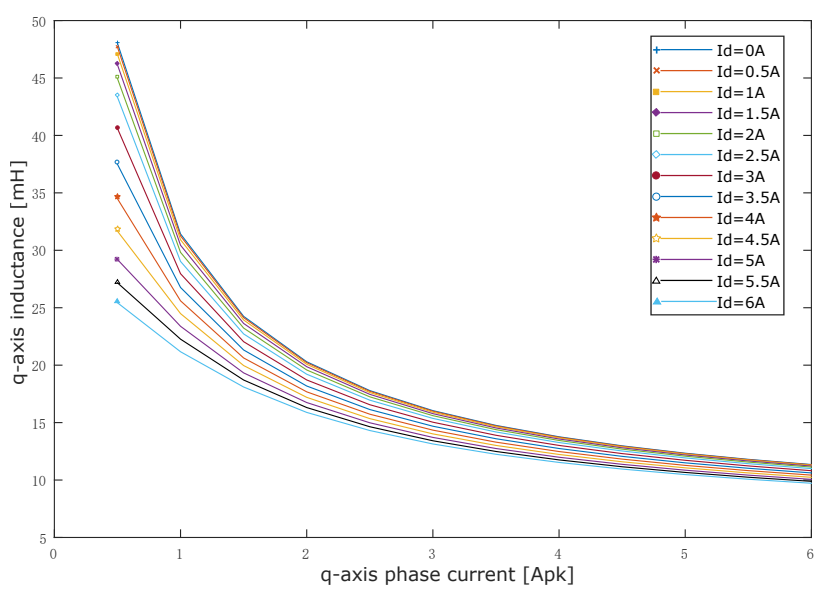

Fig. 9. Lq versus lq: cross saturation effect on motor M1.

- the power factor increases from 0.62 in M1 to 0.72 in M3, which is a $16.1 \%$ improvement;

- The current decrease in M2 and M3 results in the lower copper and iron losses;

- which in the end contributes to an efficiency improvement from $92.6 \%$ in $\mathrm{M} 1$, to $93.3 \%$ in $\mathrm{M} 2$ and $93.8 \%$ in $\mathrm{M} 3$.

This type of machine presents only reluctance torque. Its production depends on the $d$ and $q$ axis inductance difference $\left(L_{d}-L_{q}\right)$, or more commonly saliency ratio $\left(L_{d} / L_{q}\right)$, which are affected by saturation and cross saturation effects. Therefore, the analysis of the inductance behaviour, of M1 and M3 motors, is offered in Fig. 9, Fig. 10 and Fig. 11. For both machines, the $L_{q}$ inductances are presented as a function of $I_{q}$, for different $I_{d}$ values in Fig. 9 and Fig. 10 respectively. The cross saturation of M3 is relatively small, as the variation of $L_{q}$ is less than $1 \mathrm{mH}$ when the $I_{d}$ is varying from $0 \mathrm{Apk}$ to 6Apk, for $I_{q}$ current value, as shown in Fig. 10. However, the variation of $L_{q}$ in $\mathrm{M} 1$ is relatively large especially at low $I_{q}$ as shown in Fig. 9. In M1, the $L_{q}$ decreases from $48 \mathrm{mH}$ to $25 \mathrm{mH}$ when $I_{d}$ varies from $0 \mathrm{Apk}$ to $6 \mathrm{Apk}$, for an $I_{q}$ of $0.5 \mathrm{Apk}$. As a result, it is clear that $\mathrm{M} 3$ presents less cross saturation effect with respect to M1. This is due to the poor saturation of the iron ribs in M1 at low current condition. The poor saturation

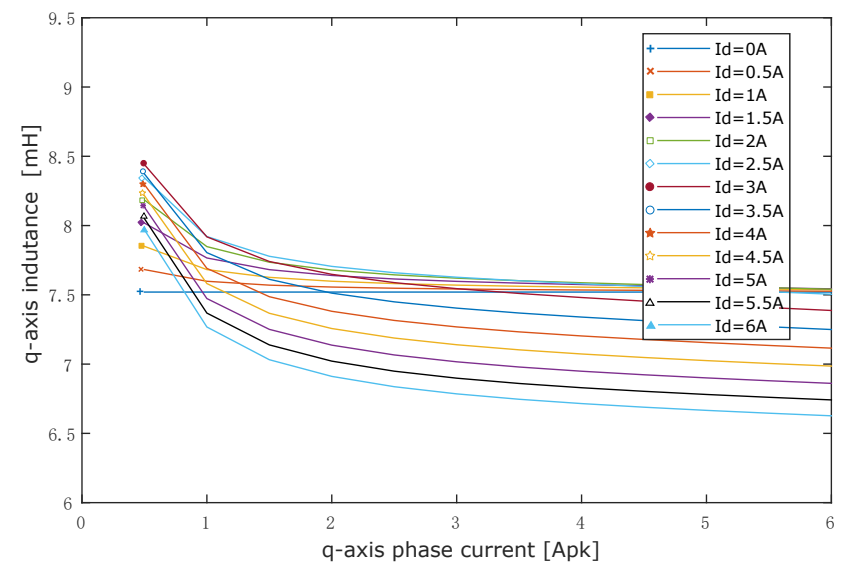

Fig. 10. Lq versus lq: cross saturation effect on motor M3.

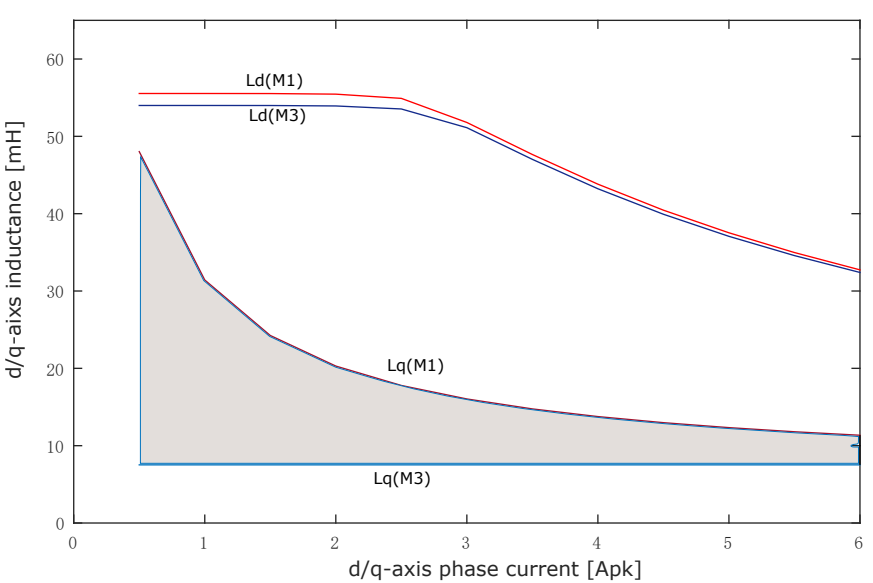

Fig. 11. Inductance of $\mathrm{M} 1$ and $\mathrm{M} 3$ with no cross saturation.

also results in relatively large $L_{q}$ in M1 compared to $L_{q}$ in M3 at low currents. The $L_{q}$ in M1 is almost comparable to its $L_{d}$ value as shown in Fig. 11 for currents below 1Apk whereas the $L_{q}$ in $\mathrm{M} 3$ appears almost constant in a small value around $8 \mathrm{mH}$ with respect to both $I_{d}$ and $I_{q}$. In M3, $L_{q}$ is much smaller compared to $\mathrm{M} 1$ and the inductance difference is particularly large under low current load condition. It can be concluded that the enhanced torque of M3 is determined by the difference of $L_{q}$, which is represented by the area highlighted in Fig. 11, between inductance profiles of M1 and M3, respectively.

M1 and M3 are compared in detail since they represent the benchmark machine and the proposed novel rotor respectively. A summary of their main parameters is given in Table IV. From the simulation results reported, M3 is capable of delivering higher average torque, power, efficiency and power factor for the same input voltage thanks to the novel rotor with higher saliency ratio.

TABLE IV

M1 AND M3 SUMmaRY AT RATEd CONDITION

\begin{tabular}{cccc}
\hline \hline Motor & M1 & M3 & unit \\
\hline Torque $T_{a v}$ & 1.15 & 1.35 & $\mathrm{Nm}$ \\
\hline Speed $\omega$ & 6000 & 6000 & $\mathrm{rpm}$ \\
\hline Power $P_{\text {out }}$ & 723.6 & 848.2 & $\mathrm{~W}$ \\
\hline Phase voltage $V_{p h}$ & 188 & 188 & $\mathrm{Vpk}$ \\
\hline DC link voltage $V_{d c}$ & 325 & 325 & $\mathrm{~V}$ \\
\hline Phase current $I_{p h}$ & 4.62 & 4.51 & $\mathrm{Apk}$ \\
\hline d-axis inductance $L_{d}$ & 53 & 52 & $\mathrm{mH}$ \\
\hline q-axis inductance $L_{q}$ & 13.4 & 7.6 & $\mathrm{mH}$ \\
\hline Efficiency $\eta$ & 92.6 & 93.7 & $\%$ \\
\hline Power factor $\lambda$ & 0.62 & 0.72 & - \\
\hline Phase resistance at $20^{\circ} \mathrm{C}$ & 1.1 & 1.1 & $\mathrm{Ohm}^{\circ}$ \\
\hline Lamination material & $\mathrm{M} 235-35 \mathrm{~A}$ & $\mathrm{M} 235-35 \mathrm{~A}$ & - \\
\hline Resin material & - & $\mathrm{E}-120 \mathrm{HP}$ & - \\
\hline Volume with housing & $1.5^{*} 10^{6}$ & $1.5^{*} 10^{6}$ & $\mathrm{~mm}{ }^{3}$ \\
\hline \hline
\end{tabular}




\section{Torque Sensitivity Analysis of the Novel RIBLESS SYNREL}

All SynRel motors, if are not well designed, can present a very high torque ripple [10], which is due to the interaction between the spatial harmonics of Magnetic Motive Force (MMF) from the stator currents and the rotor geometry [7]. As a result, besides investigating the motor behaviour, it is also essential to establish the influence of the various design parameters of the novel ribless SynRel rotor. Before starting the torque sensitivity analysis, it is necessary to recall the optimized parameters of $\mathrm{M} 3$ shown in Table. II. The motor has an average torque of $1.35 \mathrm{Nm}$ and $16 \%$ torque ripple at the rated current condition (in MTPA mode). The torque behaviour is calculated on 60 electrical degrees, corresponding to a complete cycle for a three-phase machine and it is computed by means of Maxwell stress tensor.

In Fig. 12, the average torque, expressed in pu, is represented as a function of the barrier position angles $\vartheta_{b 2}$ and $\vartheta_{b 3}$. The optimal solution is represented by the red dot (corresponding to $\vartheta_{b 3}=39.18 \mathrm{deg}, \vartheta_{b 2}=27.36 \mathrm{deg}$ ). It appears that the average torque remains almost the same (the variation is less than $2 \%$ ).

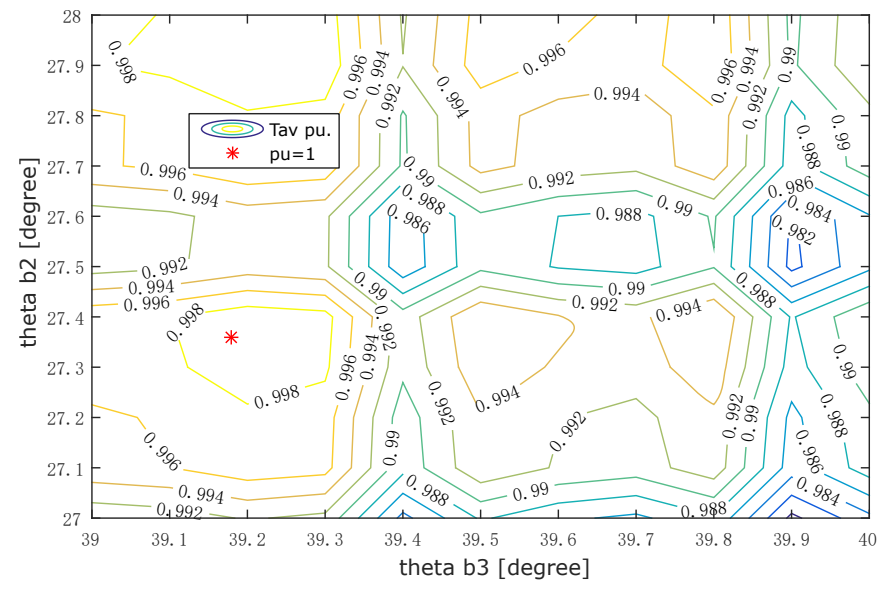

Fig. 12. Average torque as a function of $\vartheta_{b 2}$ and $\vartheta_{b 3}$ (M3).

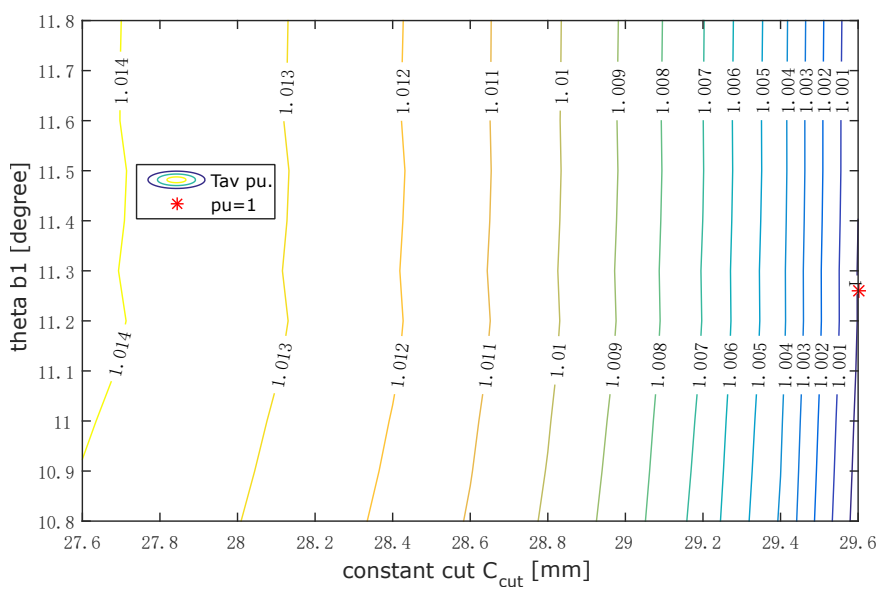

Fig. 13. Average torque as a function of $C_{c u t}$ and $\vartheta_{b 1}(\mathrm{M} 3)$.
The influence of the cut-off region has also been taken into account. As shown in Fig. 13, the average torque is not affected by the angle $\vartheta_{b 1}$ and for each $C_{c u t}$ value it remains almost constant. Besides, the position of cut-off region on q-axis $C_{c u t}$ has little impact on average torque (only $1.4 \%$ difference for a variation of $2 \mathrm{~mm}$ ).

Similar analysis is conducted on the torque ripple to understand the effects of the geometry. As shown in Fig. 14, the torque ripple is very sensitive with respect to $\vartheta_{b 3}$ variation. When $\vartheta_{b 3}$ varies from the optimal value $39.18 \mathrm{deg}$ to $40 \mathrm{deg}$, with $\vartheta_{b 2}$ equal to $27.36 \mathrm{deg}$, the torque ripple increases from $16 \%$ to more than $48 \%$. Meanwhile, $\vartheta_{b 2}$ has less influence on torque ripple compared to $\vartheta_{b 3}$. Moving the angle from 27.36 deg to $28 \mathrm{deg}$, with $\vartheta_{b 3}$ constant to $39.18 \mathrm{deg}$, the torque ripple increases from $16 \%$ to about $26 \%$.

As the novel rotor is completely ribless, it is worth to consider the torque ripple sensitivity of barrier end opening angles $\Delta b 2$ and $\Delta b 3$. In Fig. 15 , it can be seen that the torque ripple is optimal when the two angles are kept as a combination of relatively small values (i.e. $0.72 \mathrm{deg}$ for $\Delta b 2$ and $0.8 \mathrm{deg}$ for $\Delta b 3$, in this case). Even if these two parameters have less effect on torque ripple, compared to the

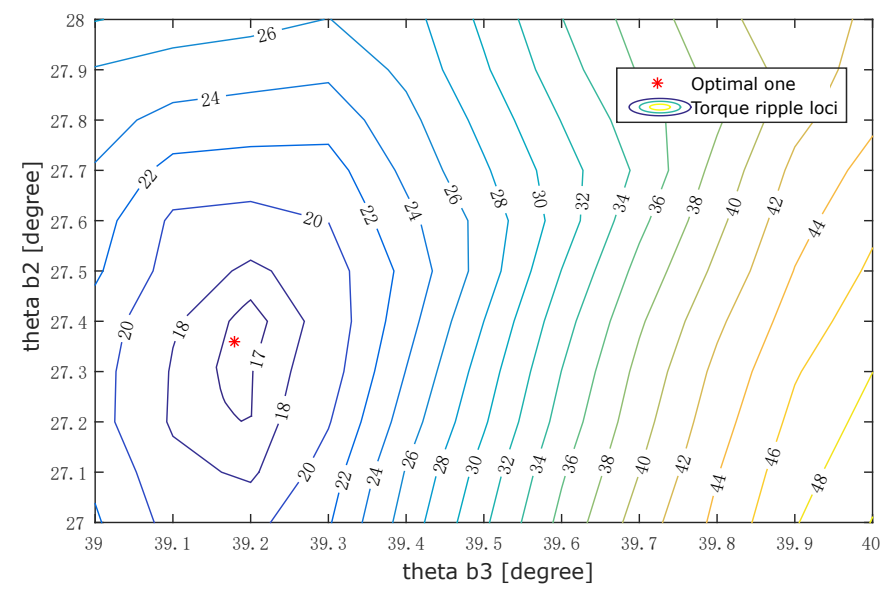

Fig. 14. Torque ripple as a function of $\vartheta_{b 2}$ and $\vartheta_{b 3}(\mathrm{M} 3)$.

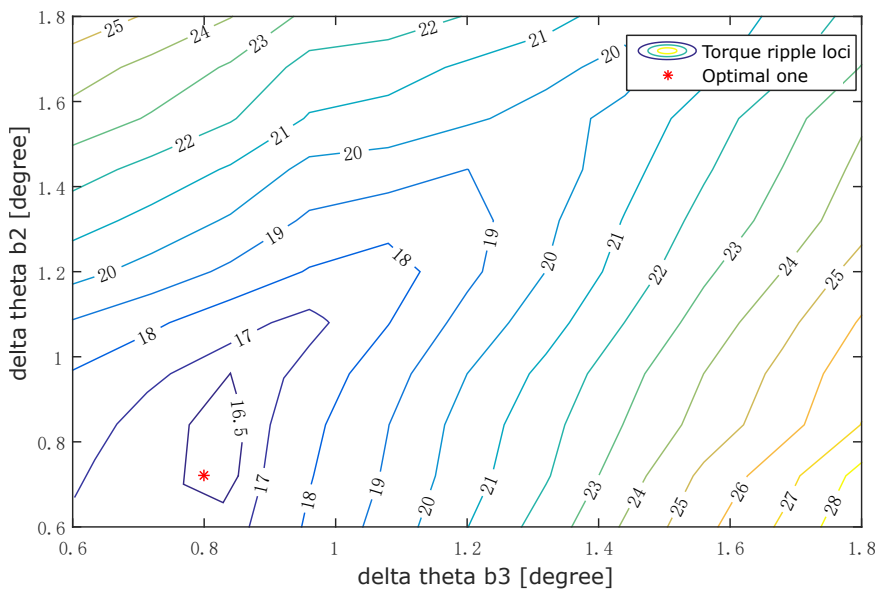

Fig. 15. Torque ripple as a function of $\Delta_{b 2}$ and $\Delta_{b 3}(\mathrm{M} 3)$. 


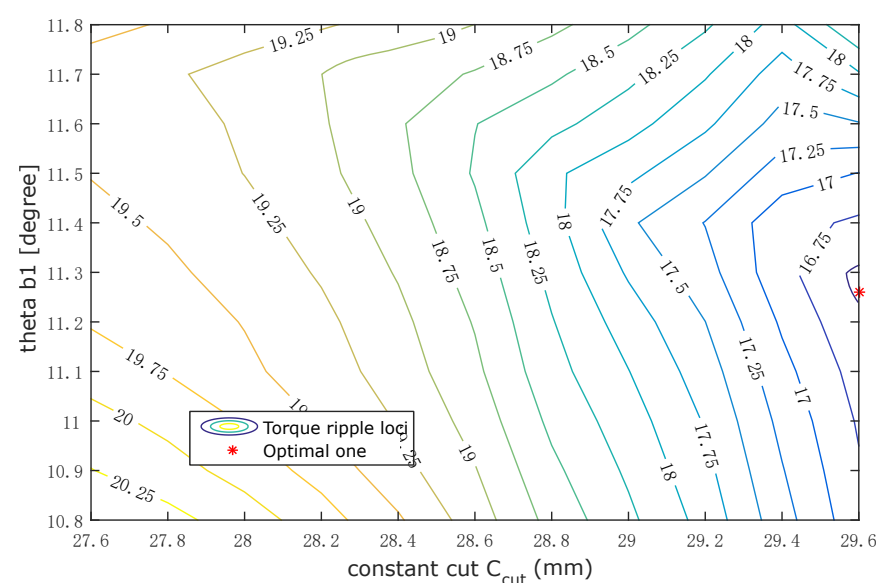

Fig. 16. Torque ripple as a function of the design variables $C_{c u t}$ and $\vartheta_{b 1}(\mathrm{M} 3)$.

barrier position angles $\vartheta_{b 2}$ and $\vartheta_{b 3}$, they are still essential for torque ripple reduction.

Similar torque ripple sensitivity analysis can be done on $C_{c u t}$ and $\vartheta_{b 1}$, as shown in Fig. 16. Starting from the optimal solution, it is interesting to notice that the torque ripple decreases as $C_{c u t}$ increases, with $\vartheta_{b 1}$ kept constant to its optimal value of 11.26 deg. It exhibits an opposite behaviour with respect to the average torque. To conclude, the above sensitivity analysis confirms the importance of selecting the rotor parameters in order to reduce the torque ripple. Also, its oscillations are more sensitive to the geometry parameters with respect to the average torque. Similar behaviour has been identified on the conventional SynRel motor.

\section{Structural Analysis and ManUfacturability}

Conventional SynRel motor rotors have iron ribs (tangential and central bridges) to maintain the mechanical stability against centrifugal force. The novel rotor instead only relies on the adhesive resin and its mechanical properties to hold the structure. In this section a summary of the structural and manufacturing considerations applied is given.

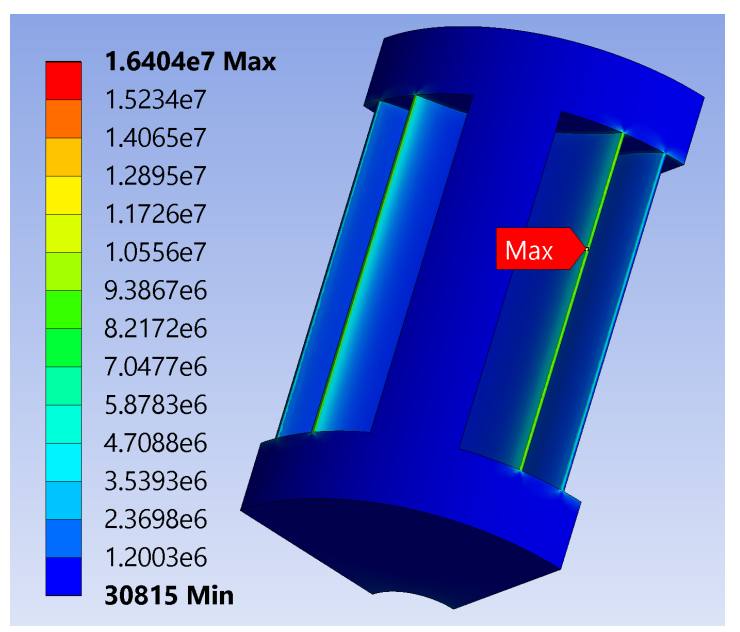

Fig. 17. Von-mises stress $[\mathrm{Pa}]$ of the material at 16000rpm.

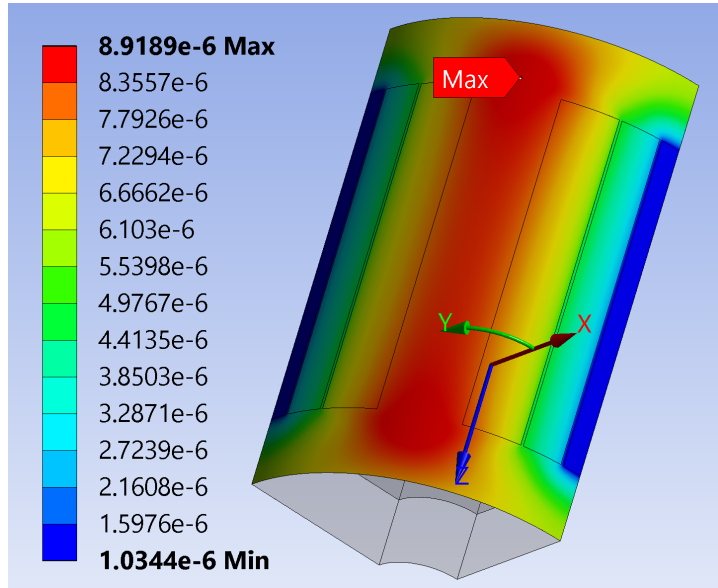

Fig. 18. Deformation [m] of the novel rotor at 16000rpm.

\section{A. Structural Analysis}

Since the rotor maximum speed is designed as 16000rpm, a mechanical finite element simulation is carried out to verify its integrity against centrifugal forces. The analysis is carried out by simulating one rotor symmetry with ANSYS software. The injected material is an industrial grade epoxy resin with high adhesive properties, good mechanical strength and temperature resistance when it is fully cured. Basically, it is an epoxy material with two components with the mechanical properties shown in Table V.

Since there is no load along the rotor axis, its iron parts are modeled as a consistent isotropic material along the axis to reduce the model complexity. All contacts between resin and iron are set as bonded, meaning that sliding or separation between two materials is not allowed. It is necessary to determine the Von-Mises stress on the rotor epoxy regions. As shown in Fig. 17, the small barrier end opening regions is the one showing highest Von-Mises stress. However, its value is $16.5 \mathrm{MPa}$ at $16000 \mathrm{rpm}$, which is less than half of the material limit. The deformation status of the rotor at 16000rpm is displayed in Fig. 18. The maximum deformation occurs in correspondence to the cut-off region and is less than $0.01 \mathrm{~mm}$, which is considered acceptable.

A number of over-speed tests have been carried out to

TABLE V

ROTOR MECHANICAL PROPERTIES

\begin{tabular}{ccc}
\hline \hline $\begin{array}{c}\text { Resin type } \\
\text { Iron type }\end{array}$ & $\begin{array}{c}\text { E-120HP } \\
\text { M235-35A }\end{array}$ & \\
\hline \hline Property & Value & unit \\
\hline Mass Density(resin) & 1100 & $\mathrm{~kg} / \mathrm{m}^{2}$ \\
Young's Modulus(resin) & 3780 & $\mathrm{MPa}$ \\
Tensile Yield Strength(resin) & 41 & $\mathrm{MPa}$ \\
Poisson's Ratio(resin) & 0.35 & - \\
\hline Mass Density(iron) & 7600 & $\mathrm{~kg} / \mathrm{m}^{2}$ \\
Young's Modulus(iron) & 200 & $\mathrm{GPa}$ \\
Tensile Yield Strength(iron) & 460 & $\mathrm{MPa}$ \\
Poisson's Ratio(iron) & 0.3 & - \\
\hline \hline
\end{tabular}




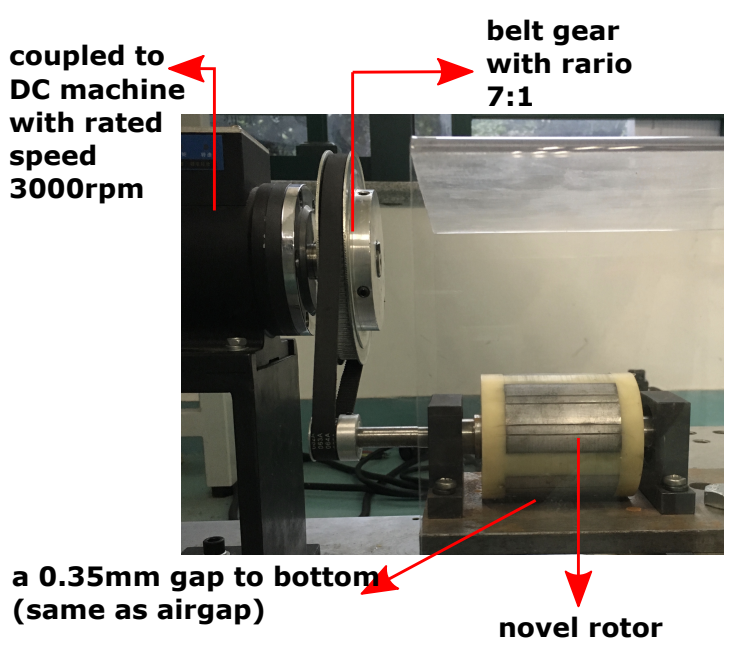

Fig. 19. Speed validation rig.

ensure that the rotor can maintain mechanical integrity. The rig for speed test is shown in Fig. 19. In order to simulate critical temperature scenarios, the rotor, together with the bearing supports and base shown in Fig. 19, is first heated up in the oven for one hour to a certain temperature. After that, the rotor diameter is measured as $D 2$ and compared to the initial rotor diameter $D 1$ to check thermal expansion. Then the rotor is placed onto the speed test rig to spin for 30 minutes, driven by the master motor through the belt. At the end of the test, the rotor diameter is measured again as D3 to check if any deformation has occurred. The tests have been performed at $60^{\circ} \mathrm{C}, 80^{\circ} \mathrm{C}, 100^{\circ} \mathrm{C}$ and $120^{\circ} \mathrm{C}$. The qualitative results have shown that the deformations of the rotor are always less than $0.01 \mathrm{~mm}$ compared to $D 1$, which proves that the prototype is capable of operating at temperature up to $120^{\circ} \mathrm{C}$. Additionally, there is a $0.35 \mathrm{~mm}$ gap between the rotor outer surface and the bottom plate resembling the air gap in real motor, so that any deformation will be observed if the deformation of the rotor becomes too large during the tests. However, no destructive experiments have been performed so far to identify the exact breaking point. The limitations of the materials, from both thermal and mechanical point of view need to be further explored. However, to the purpose of validating the feasibility of the novel concept, proposed in this paper, a number of experimental results are offered in section V.

\section{B. Manufacturability}

The manufacturing process of the M3 rotor protype is described as below:

- Step 1: A rotor core with ribs (initial laminations with ribs in Fig. 20(a)) is manufactured with conventional process by wire cutting laminations bolted together. The width of the ribs is designed to be thin and consistent to the diameter of the rotor, which is marginally larger than the final product to provide allowance for follow-up machining.

- Step 2: A mold as shown in Fig. 20(a) is used. It consists of two parts: a cylindrical outer casing (mold part1), which encapsulates the rotor, and a shaft insert (mold

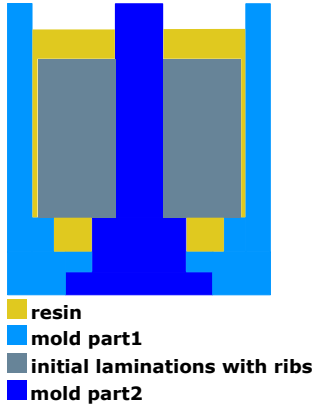

(a)

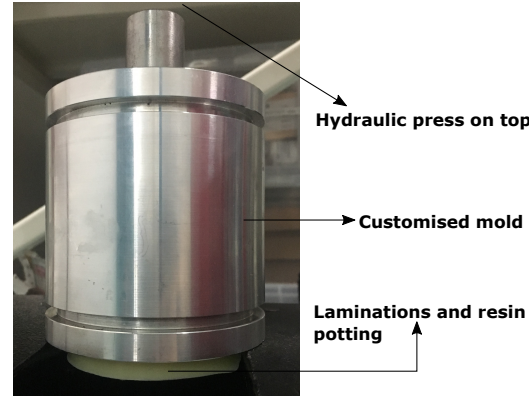

(b)
Fig. 20. Rotor assembly: Resin and laminations assembly (a). extraction tool (b).

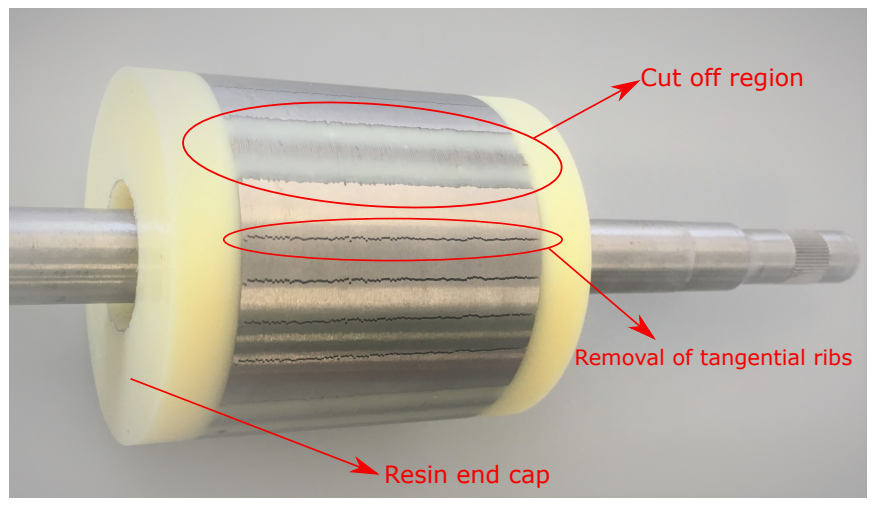

Fig. 21. Novel SynRel rotor without ribs (M3).

part2) used to positioning the rotor at the center and prevent resin from entering the shaft hole in the rotor core. The resin is poured into the mold first. Then the rotor core is pressed down to the bottom of the mold, pushing the resin to fill up the flux barriers and the cavity between the rotor core and the mold. After the resin cured, the rotor core and the resin become a whole part and is removed from the mold by a hydraulic press for further processing as shown in Fig. 20(b).

- Step 3: The outer layer of rotor is machined away to remove the ribs and excess resin so that final dimensions are achieved. The iron islands are mechanically separated while being held together solely by resin.

A picture of the final manufacutred novel rotor with shaft is shown in Fig. 21.

\section{EXPERIMENTAL VALIDATION}

In order to verify the electromagnetic torque characteristics of the proposed SynRel, M1 and M3 have been manufactured and tested. The experimental measurements are performed on the machine mechanically coupled with a Magtrol setup (Dynamometer, Hysteresis Brake and Torque Sensor). The Magtrol controller has a minimum torque resolution of $0.001 \mathrm{Nm}$. The motor is driven by a smart power module STK5Q4U362J and controlled by the 32-bit Toshiba TMPM375 microcontroller. The rotor position is measured by means of an encoder. 


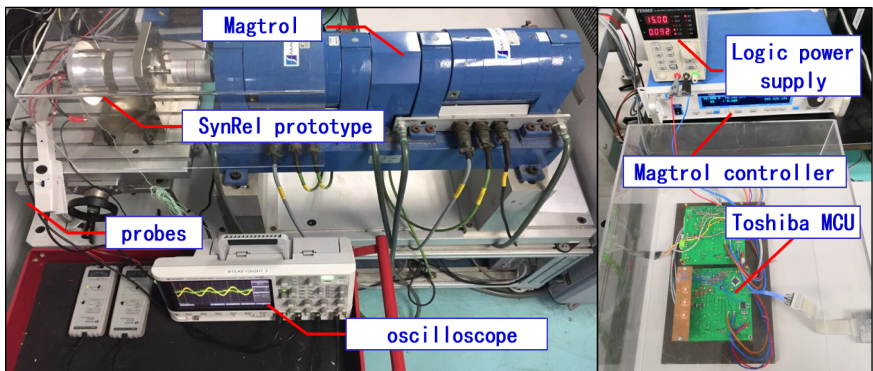

Fig. 22. Magtrol rig for experimental test.

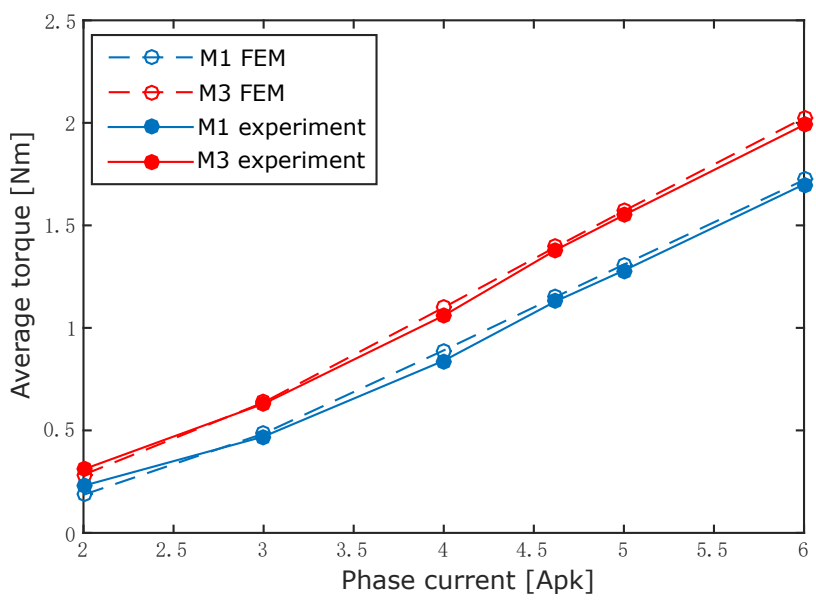

Fig. 23. Experimental and FEM torque results comparison.

A picture of the Magtrol rig is shown in Fig. 22, highlighting the main test rig components. The experimental torque results are shown in Fig. 23. For both prototypes, the torque has been measured for different current values (from 2Apk to 6Apk). The measurements have been compared with the simulation results carried out by means of FEA. The torque versus current characteristics are showing a very good agreement with FEA results for both machines. Considering the current 4.6Apk, the average torque of $\mathrm{M} 3$ is $1.38 \mathrm{Nm}$, which is $22.1 \%$ larger with respect to the $1.13 \mathrm{Nm}$ in $\mathrm{M} 1$.

A summary of the torque increment given by the novel motor design is given in Table VI. It is clearly showing that the torque is enhanced for any current loading. Furthermore, it confirms the prediction estimated by means of finite element simulations that has been shown Fig. 8, giving an improvement of the same order (about 22.1\%). This means that the proposed motor can achieve the same torque with a reduced current

TABLE VI

EXPERIMENTAL TORQUe RESULTS ALONG MTPA

\begin{tabular}{cccc}
\hline \hline Current [Apk] & M1 [Nm] & M3 [Nm] & T increase [\%] \\
\hline 2 & 0.23 & 0.31 & 34.8 \\
3 & 0.47 & 0.63 & 34 \\
4 & 0.84 & 1.06 & 26.2 \\
4.6 (M1 rated) & 1.13 & 1.38 & 22.1 \\
5 & 1.28 & 1.55 & 21.1 \\
6 & 1.7 & 1.99 & 17.1 \\
\hline \hline
\end{tabular}

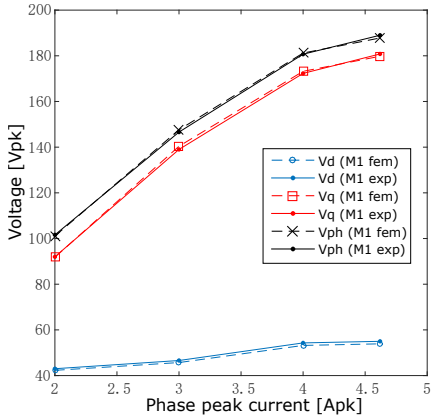

(a) M1

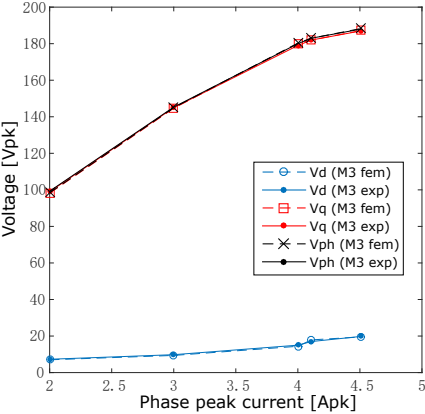

(b) $\mathrm{M} 3$
Fig. 24. Experimental voltage results comparison with FEM: M1(a). M3(b).

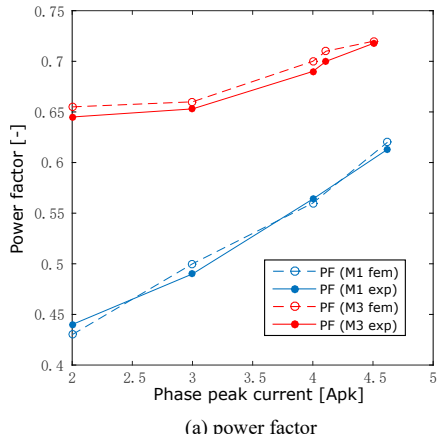

(a) power factor

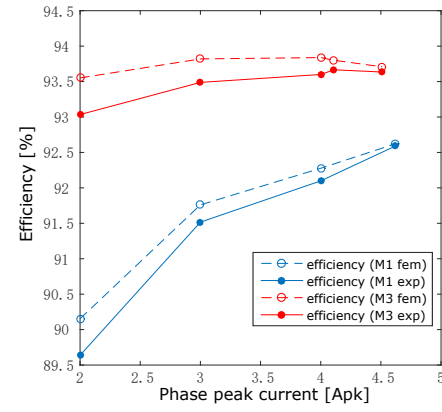

(b) Efficiency
Fig. 25. Experimental power factor and efficiency results comparison with FEM: Power factor(a). Efficiency(b).

(more than 10\% reduction), with a consequent improvement of the copper losses.

Further experimental results are presented in Fig. 24 and Fig. 25. The first is showing the experimental voltages captured at 6000rpm at different current values. The results are in good agreement with the ones carried out via finite element and their difference is within 2\%. In Fig. 24(b), the phase peak voltage $V_{p h}$ and $V_{q}$ of motor M3 have similar values since $V_{d}$ is relatively small. The measured phase voltage is $189 \mathrm{Vpk}$ in $\mathrm{M} 1$ and $188.3 \mathrm{Vpk}$ in $\mathrm{M} 3$ at rated condition.

Power factor and efficiency are shown in Fig. 25 for both M1 and M3, at the rated speed of 6000rpm. FEA predictions are validated with a difference within $3 \%$ and $1 \%$ for power factor and efficiency respectively. Compared to M1, for different set points of current (2Apk, 3Apk and 4Apk), both power factor and efficiency are showing higher values in motor M3.

\section{CONCLUSIONS}

This paper has proposed a novel structural and electromagnetic concept of SynRel motor completely without iron ribs (M3). A detailed analysis of the novel SynRel on torque production is carried out, showing the impact level of each rotor geometry parameter and an optimal range for opening the rotor barrier angle. The analysis shows how the $d q$-axis inductances are changing with respect to the conventional SynRel motor (M1). First, the simulations results showing the advantages of the novel SynRel motor proposed are analysed. 
The high speed capability of the novel SynRel is verified both via mechanical FEA analysis followed by an over speed validation test at high temperature. The manufacturing process has been described in detail. Finally, a number of experimental results have been shown and it has been validated that the proposed novel rotor design can lead to improve torque, power factor and efficiency. These are justified by the enhanced saliency ratio and minimised cross saturation effects given by the absence of the iron ribs. The results are showing an enhanced capability of novel SynRel for any current loading compared to conventional SynRel.

\section{REFERENCES}

[1] A. Vagati, "The synchronous reluctance solution: a new alternative in ac drives." Industrial Electronics, Control and Instrumentation, 1994. IECON '94., 20th International Conference on, vol. 1, Sep 1994, pp. 1-13 vol.1.

[2] A. Boglietti, A. Cavagnino, M. Pastorelli and A. Vagati, 'Experimental comparison of induction and synchronous reluctance motors performance," Fourtieth IAS Annual Meeting. Conference Record of the 2005 Industry Applications Conference, 2005., 2005, pp. 474-479 Vol. 1.

[3] A. T. de Almeida, F. J. T. E. Ferreira and G. Baoming, "Beyond Induction Motors?Technology Trends to Move Up Efficiency," in IEEE Transactions on Industry Applications, vol. 50, no. 3, pp. 2103-2114, May-June 2014

[4] R. R. Moghaddam and F. Gyllensten, "Novel High-Performance SynRM Design Method: An Easy Approach for A Complicated Rotor Topology,' in IEEE Transactions on Industrial Electronics, vol. 61, no. 9, pp. 50585065, Sept. 2014.

[5] R. Rajabi Moghaddam, "Synchronous Reluctance Machine (SynRM) in Variable Speed Drives (VSD) Applications", Ph.D. dissertation, Stockholm, 2011.

[6] Michele Degano, "Analysis, Design and Optimization of Innovative Electrical Machines Using Analytical and Finite Element Analysis Methods", Ph.D. dissertation, Padova Univ., Veneto, Italy, 2014.

[7] A. Vagati, M. Pastorelli, G. Franceschini, and S.C. Petrache. "Design of low-torque-ripple synchronous reluctance motors." IEEE Trans. on Industry Application, IA-34(4):758-765, July-Aug. 1998.

[8] M. Muteba, B. Twala and D. V. Nicolae, "Torque ripple minimization in synchronous reluctance motor using a sinusoidal rotor lamination shape," 2016 XXII International Conference on Electrical Machines (ICEM), Lausanne, 2016, pp. 606-611.

[9] A. Arafat and S. Choi, "Active Current Harmonic Suppression for Torque Ripple Minimization at Open Phase Faults in a Five-Phase PMaSynRM," in IEEE Transactions on Industrial Electronics, April. 2018.

[10] N. Bianchi, M. Degano and E. Fornasiero, "Sensitivity Analysis of Torque Ripple Reduction of Synchronous Reluctance and Interior PM Motors," in IEEE Transactions on Industry Applications, vol. 51, no. 1, pp. 187-195, Jan.-Feb. 2015.

[11] A. Fratta, A. Vagati, and F. Villata. "Permanent magnet assisted synchronous reluctance drive for constant-power application: Drive power limit." In Proc. of Intelligent Motion European Conference, PCIM, pages 196-203, April Nurnberg, Germany, 1992.

[12] M. J. Kamper, A. F. Volsdhenk, ”Effect of rotor dimensions and cross magnetisation on $\mathrm{Ld} / \mathrm{Lq}$ inductances of reluctance synchronous machine with cageless flux barrier rotor", IEE Proceedings- Electric Power Applications, vol. 141, pp. 213-220, 1994.

[13] F. N. Isaac, A. A. Arkadan and A. El-Antably, "Characterization of axially laminated anisotropic-rotor synchronous reluctance motors," in IEEE Transactions on Energy Conversion, vol. 14, no. 3, pp. 506-511, Sep 1999.

[14] A. Vagati, M. Pastorelli, F. Scapino and G. Franceschini, "Impact of cross saturation in synchronous reluctance motors of the transverselaminated type," in IEEE Transactions on Industry Applications, vol. 36, no. 4, pp. 1039-1046, Jul/Aug 2000.

[15] W.H. Kim, K.S. Kim, S.J. Kim, D.W. Kang, S.C. Go, Y.D. Chun, J. Lee, "Optimal PM Design of PMA-SynRM for Wide ConstantPower Operation and Torque Ripple Reduction," IEEE Transactions on Magnetics, vol. 45, no. 10, pp. 4660-4663, Oct. 2009.
[16] M. Degano, E. Carraro and N. Bianchi, "Selection Criteria and Robust Optimization of a Traction PM-Assisted Synchronous Reluctance Motor,' in IEEE Transactions on Industry Applications, vol. 51, no. 6, pp. 4383-4391, Nov.-Dec. 2015.

[17] C. M. Donaghy-Spargo, "Electromagnetic?Mechanical Design of Synchronous Reluctance Rotors With Fine Features,' in IEEE Transactions on Magnetics, vol. 53, no. 11, pp. 1-8, Nov. 2017.

[18] C. Babetto, G. Bacco and N. Bianchi, "Synchronous Reluctance Machine Optimization for High Speed Applications," in IEEE Transactions on Energy Conversion, Jan. 2018.

[19] J. K. Tangudu and T. M. Jahns, ”Comparison of Interior PM Machines with Concentrated and Distributed Stator Windings for Traction Applications," 2011 IEEE Vehicle Power and Propulsion Conf. (VPPC), pp. 1-8, 6-9 Sep. 2011.

[20] L. Chong and M. F. Rahman, "Saliency ratio derivation and optimisation for an interior permanent magnet machine with concentrated windings using finite-element-analysis," IET Electric Power Applications, vol. 4, no. 4, pp. 249-258, Apr. 2010.

[21] J. H. Mathews, R. W. Howell, "Complex analysis for mathematics amd engineering?, 4th edition, Jones and Bartlett Publishers, 2001, ISBN 0-7637-1425-9.

[22] Poles S., " MOGA-II An improved Multi-Objective Genetic Algorithm”, Technical Report 2003-006.

[23] G. Pellegrino, F. Cupertino and C. Gerada, "Automatic Design of Synchronous Reluctance Motors Focusing on Barrier Shape Optimization," in IEEE Transactions on Industry Applications, vol. 51, no. 2, pp. 1465 1474, March-April 2015. doi: 10.1109/TIA.2014.2345953.

[24] M. Degano, M. Di Nardo, M. Galea, C. Gerada and D. Gerada, "Global design optimization strategy of a synchronous reluctance machine for light electric vehicles," 8th IET International Conference on Power Electronics, Machines and Drives (PEMD 2016), Glasgow, 2016, pp. $1-5$.

[25] M. Di Nardo, M. Galea, C. Gerada, M. Palmieri, F. Cupertino and S Mebarki, "Comparison of multi-physics optimization methods for high speed synchrnous reluctance machines," IECON 2015 - 41st Annual Conference of the IEEE Industrial Electronics Society, Yokohama, 2015, pp. 002771-002776.

[26] M. D. Nardo, G. L. Calzo, M. Galea and C. Gerada, 'Design Optimization of a High-Speed Synchronous Reluctance Machine," in IEEE Transactions on Industry Applications, vol. 54, no. 1, pp. 233-243, Jan.Feb. 2018

[27] W. T. Villet and M. J. Kamper, "Variable-Gear EV Reluctance Synchronous Motor Drives?An Evaluation of Rotor Structures for PositionSensorless Control," in IEEE Transactions on Industrial Electronics, vol. 61, no. 10, pp. 5732-5740, Oct. 2014.

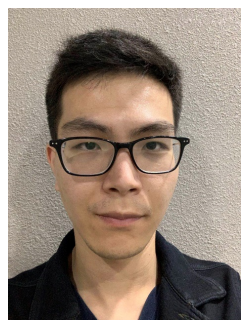

Yuli Bao received B.Eng. degree in electrical engineering and renewable energy systems from the University of Nottingham, Nottingham, U.K., in 2013 . He is currently pursuing a Ph.D degree at University of Nottingham Ningbo China with a focus on novel synchronous reluctance motor design and optimization. His main research interests include design and optimization of highperformance synchronous reluctance motors for industrial and household applications.

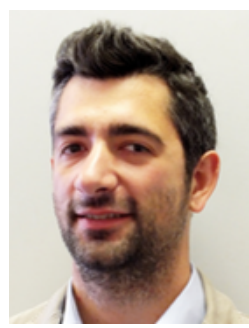

Michele Degano (M'15) received the Laurea degree in electrical engineering from the University of Trieste, Trieste, Italy, in 2011, and the $\mathrm{Ph} . \mathrm{D}$. degree in industrial engineering from the University of Padova, Padova, Italy, in 2015. During his doctoral studies, he cooperated with several companies for the design of permanentmagnet machines. In 2015, he joined the Power Electronics, Machines and Control Group, The University of Nottingham, Nottingham, U.K., as a Research Fellow, where he is currently an Assistant Professor teaching advanced electrical machines design modules. His main research interests include design and optimization of permanent-magnet machines, reluctance and permanent-magnetassisted synchronous reluctance motors through genetic optimization techniques, for industrial, automotive and aerospace applications, ranging from small to large power. He is currently leading research projects for the development of future hybrid electric aerospace platforms. 


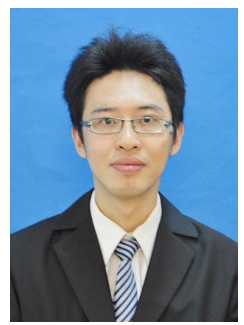

Shuo Wang (S'17-M'19) received the bachelor degree in automation from Hebei university of Technology in 2011, Tianjin, China, master degree in control science and engineering from Tianjin University in 2014, Tianjin, China, and $\mathrm{Ph} . \mathrm{D}$. degree in control science and engineering from Tongji University in 2019, Shanghai, China. From 2017 to 2018, he became a Visiting researcher with Power Electronics, Machines and Control Group (PEMC Group), University of Nottingham, Nottingham, U.K. He is currently working as a visiting researcher in Nottingham Electrification Centre (NEC) within the Power electronics, Machines and Control research group in University Of Nottingham. His current research interests include highperformance torque control, sensorless control and flux-weakening control used for permanent magnet synchronous machines, synchronous reluctance machines and permanent magnet-assisted synchronous reluctance machines.

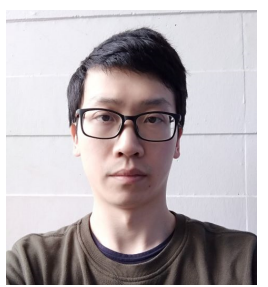

Chuan Liu received B.Eng. degree in mechanical engineering from Nanjing Agricultural University, Nanjing, China, in 2015. He is currently a Ph.D. student in Electrical and Electronic Engineering at the University of Nottingham Ningbo China. He is currently working on structural design and innovative thermal management for high-power-density electrical machines.

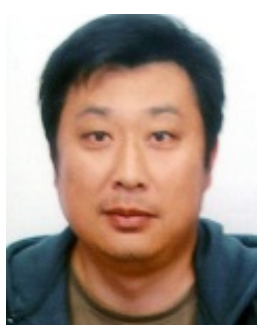

Zhuang Xu (Member of Power and Energy Society 2017) received the M.Eng.Sci. and Ph.D. degrees in electrical engineering from the University of New South Wales, Sydney, Australia in 1999 and 2006, respectively. He was with the Energy System Group, University of New South Wales, from 2001 to 2005. He became an Associate Professor with Harbin Institute of Technology, Harbin, China, in 2006, where his research was focused on power electronics and high-performance electrical drives. He is currently an Associate Professor at The University of Nottingham Ningbo China. Dr. Xu was the recipient of three Best Paper Awards at IECON'04 IEEE ICEMS 2010, and IEEE ECCE-Asia ICPE 2011, respectively.

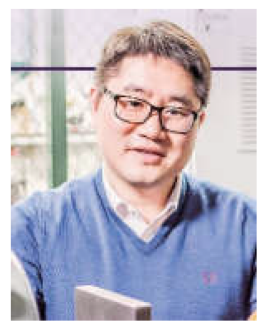

He Zhang received his B.Eng. degree from Zhejiang University, China, in 2002. He obtained the MSc. and Ph.D. degree in electrical machines from The University of Nottingham, UK, in 2004 and 2009 respectively. After this he worked as Research Fellow at the University and Director of BestMotion Technology Centre. He moved to University of Nottingham Ningbo China as Senior Research Fellow in 2014 and Principal Research Fellow in 2016. Currently he is the Director of Nottingham Electrification Centre (NEC) within the Power electronics, Machines and Control research group in University of Nottingham. His research interests include highperformance electric machines and drives for transport electrification.

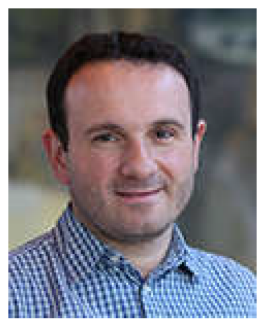

Chris Gerada (M'05-SM'12) received the Ph.D. degree in numerical modelling of electrical machines from The University of Nottingham, Nottingham, U.K., in 2005. He subsequently worked as a Researcher with The University of Nottingham on high-performance electrical drives and on the design and modelling of electromagnetic actuators for aerospace applications. In 2008, he was appointed as a Lecturer in electrical machines; in 2011, as an Associate Professor; and in 2013, as a Professor at The University of Nottingham. He was awarded a Research Chair from the Royal Academy of Engineering in 2013 and his main research interests include the design and modelling of high-performance electric drives and machines. Prof. Gerada serves as an Associate Editor for the IEEE TRANSACTIONS ON INDUSTRY APPLICATIONS and is the past Chair of the IEEE IES Electrical Machines Committee. 